\title{
Immunosupppression and Endocrine Dysfunction
}

\section{Vijay Shivaswamy ${ }^{1,2 *}$, Robert G. Bennett ${ }^{1,2}$, Jennifer L. Larsen ${ }^{1,2}$, John S. Davis ${ }^{1,3,4}$ and Frederick G. Hamel ${ }^{1,2}$}

${ }^{1}$ VA Nebraska-Western lowa Health Care System, University of Nebraska Medical Center, Omaha, NE, 68198

${ }^{2}$ Departments of Internal Medicine, University of Nebraska Medical Center, Omaha, NE, 68198

${ }^{3}$ Biochemistry and Molecular Biology, University of Nebraska Medical Center, Omaha, NE, 68198

${ }^{4}$ Obstetrics and Gynecology, University of Nebraska Medical Center, Omaha, NE, 68198

\begin{abstract}
Immune suppression medications contribute to multiple aspects of endocrine dysfunction including post-transplant diabetes mellitus (PTDM), reproductive dysfunction and fracture. In this paper, we will review the available evidence, pathophysiology and prevention/treatment strategies for immunosuppression-induced endocrine dysfunction. PTDM can substantially reduce graft and patient survival after kidney transplant. Tacrolimus (TAC), which is among the most commonly used immunosuppression drugs in organ transplantation, can suppress insulin gene expression, decrease insulin release, and may cause islet cell apoptosis. Sirolimus (SIR), which is frequently used in combination with TAC for islet transplants, can decrease islet insulin secretion in vitro and may affect insulin action causing an insulin resistance state. Animal studies have shown that short term treatment with TAC or SIR can independently cause hyperglycemia with hyperinsulinemia in normal rats, suggesting insulin resistance, with greater hyperinsulinemia occurring with SIR than with TAC treatment. Together, these agents reduce insulin secretion and increase islet apoptosis. SIR acts by binding to mammalian target of rapamycin, which is a downstream protein in the insulin signal transduction cascade, but how SIR causes insulin resistance is not known. SIR and TAC have been shown to induce islet apoptosis in vitro; however, regulation of this process by immunosuppressants has not been studied. While immunosuppressants contribute to PTDM, little is known about whether it can be prevented with any current therapeutic intervention for type 2 diabetes. SIR has been associated with irregular menses and ovarian cysts, and primary hypogonadism posttransplant. SIR has been associated with delayed fracture healing, but the effect on bone density is not clear. In conclusion, predominant endocrine effects of commonly used immunosuppressive medications appear to be on the development of PTDM and reproductive dysfunction, while also potentially contributing to fractures.
\end{abstract}

\section{Immunosuppression and Hyperglycemia}

New onset diabetes after transplantation or post-transplant diabetes mellitus (PTDM) has been recognized for many years as a significant adverse consequence of solid organ transplants, including kidney. PTDM has been shown to be associated with increased risk of graft failure, fatal and nonfatal cardiovascular disease in kidney transplant recipients, and increased acute rejection in liver transplant recipients [1-4]. In the past, various clinical definitions have been used to characterize this complication, including random blood glucose $\geq$ $200 \mathrm{mg} / \mathrm{dl}$, fasting blood glucose $\geq 140 \mathrm{mg} / \mathrm{dl}$, or the need for insulin therapy in post-transplant patients. In 2003, consensus guidelines were published, based on the American Diabetes Association criteria for diagnosing type 2 diabetes, finally setting clear definitions for the diagnosis of PTDM [5]. The current guidelines for the diagnosis of PTDM are fasting plasma glucose $\geq 126 \mathrm{mg} / \mathrm{dl}$, blood glucose $\geq 200$ $\mathrm{mg} / \mathrm{dl}$ in response to a $75 \mathrm{gm}$ oral glucose tolerance test, or random blood glucose $\geq 200 \mathrm{mg} / \mathrm{dl}$ along with clinical symptoms of diabetes.

The reported incidence of PTDM varies widely in the literature based on the definitions and the type of immunosuppression used [6]. In a retrospective analysis of Medicare beneficiaries in the U.S., the cumulative incidence of new-onset diabetes after transplantation among 11,659 patients was $9.1 \%, 16 \%$, and $24 \%$ at 3 months, 12 months, and 36 months, respectively [2]. Using the current definition, Lane et al. [7] found that the incidence of PTDM in our (University of Nebraska Medical Center) database was around $74 \%$ in patients who underwent kidney transplantation between $8 / 2001$ and 3/2003 and tacrolimus and cyclosporine treatments correlated strongly with the onset of PTDM.

Commonly used immunosuppressants, calcineurin inhibitors (tacrolimus) and mammalian target of rapamycin (mTOR) inhibitors (sirolimus), have been strongly implicated in the etiology of PTDM.

\section{Calcineurin inhibitors (CNIs)}

Cyclosporine and Tacrolimus (FK506) are the commonly used calcineurin inhibitors. CNIs reduce the production of cytokines by lymphocytes, primarily by inhibiting the calmodulin-dependent serine phosphatase calcineurin and preventing the transcription of mRNAs for important cytokines, such as interleukin-2. While cyclosporine and FK506 bind to different intracellular proteins called immunophilins (cyclophilins and FK506 binding proteins (FKBP-12), they exert their action via calcineurin inhibition. After activation by an increase in intracellular calcium, calcineurin dephosphorylates the cytoplasmic subunit of nuclear factor of activation of T cells (NFAT), which then undergoes translocation to the nucleus. Subsequently NFAT transactivates genes required for T-cell activation. When CNIs bind to calcineurin, they prevent dephosphorylation of NFAT and the subsequent events leading to lack to T-cell activation $[8,9]$.

\section{mTOR inhibitors}

Sirolimus (rapamycin) and everolimus are two drugs in this class of immunosuppressants, with everolimus being the newer agent. Sirolimus binds to FKBP12 but does not inhibit calcineurin or cytokine transcription, in contrast with CNIs [10]. Instead, sirolimus inhibits a pivotal multifunctional serine-threonine kinase, mammalian target of rapamycin (mTOR), which mediates key signal-transduction pathways

*Corresponding author: Vijay Shivaswamy, MBBS, VA Nebraska-Western lowa Health Care System and Departments of Internal Medicine, University of Nebraska Medical Center, 983020 Nebraska Medical Center, Omaha, NE 68198-3020, Tel. 402-559-6205; Fax: 402-559-6205; E-mail: vshivaswamy@unmc.edu

Received November 19, 2011; Accepted January 11, 2012; Published January 16,2012

Citation: Shivaswamy V, Bennett RG, Larsen JL, Davis JS, Hamel FG (2012) Immunosuppression and Endocrine Dysfunction. J Transplant Technol Res S2:006. doi:10.4172/2161-0991.S2-006

Copyright: @ 2012 Shivaswamy V, et al. This is an open-access article distributed under the terms of the Creative Commons Attribution License, which permits unrestricted use, distribution, and reproduction in any medium, provided the original author and source are credited. 
which control the cell cycle in variety of different cell types including $\mathrm{T}$ cell proliferation [11].

While the primary function of the CNIs and mTOR inhibitors are immunosuppressive in nature, these effects do not appear to mediate the endocrine dysfunction. Rather, as we and others have shown, CNIs and mTOR inhibitors appear to have direct effects on endocrine dysfunction, especially so in inducing hyperglycemia. The direct effects on reproduction and bone metabolism are less well established.

We and others have provided evidence for the diabetogenicity of the calcineurin inhibitors tacrolimus (TAC) and cyclosporine [1216]. Results from randomized trials have shown that tacrolimus has a stronger association with onset of PTDM than cyclosporine [17]. TAC was associated with higher incidence of PTDM (18\%) compared to cyclosporine $(8 \%)$ in one study using data from United States Renal Database [18]. It has also been shown that prediabetes (2 hour blood glucose 140-199 mg/dl after a standard 75 gm glucola, per American Diabetes Association criteria [19]) was common (33\%, 12 mo posttransplant) among kidney transplant recipients on TAC based therapy [20].

Impaired insulin secretion has been implicated as one of the main causes of calcineurin inhibitor-associated PTDM [21,22]. Decreased glucokinase activity and reduced insulin gene expression have been demonstrated in animal models of calcineurin inhibitor treatment [2325]. Short term $(24 \mathrm{~h})$ treatment of human islets with TAC has been shown to increase apoptosis via up regulation of caspase-3 cleavage and activity [26]. Clinical studies involving pancreas transplant recipients have shown reversible toxicity of TAC and cyclosporine of islet cells (cytoplasmic swelling and vacuolization) [27]. Insulin resistance after kidney transplant is more prevalent in patients treated with TACbased regimen compared to a cyclosporine-based regimen $[28,29]$. We have also shown that tacrolimus induces insulin resistance in normal animals [16]. It has also been shown that hypomagnesaemia plays a role in calcineurin inhibitor-induced PTDM [30]. Suggested mechanisms are diminished insulin secretion [31], altered cellular glucose transport and altered insulin-insulin receptor interactions [32]. In summary, calcineurin inhibitors have been shown to reduce insulin secretion in many studies but can also cause insulin resistance.

Sirolimus (SIR) has been variably associated with PTDM. A retrospective study of kidney transplant recipients from 2001-2005 has provided evidence to suggest that SIR did not increase the risk of PTDM [33]. However, independent association of SIR with PTDM was suggested by data obtained from the United States Renal Database data on patients with kidney transplants [34]. SIR exerts antiproliferative effects on multiple cell types including pancreatic ductal cells and endothelial cells in vitro [35]. SIR impairs in vivo proliferation of beta cells in a pregnant mouse model [36]. Supratherapeutic doses of SIR cause apoptosis in rat and human islets [37]. In addition, SIR causes severe hypertriglyceridemia in susceptible individuals, similar to insulin resistance states, suggesting it may also affect other actions of insulin [38]. The mechanisms of SIR-induced hyperglycemia and hyperinsulinemia are unclear. We have demonstrated that SIR induces hyperglycemia and hyperinsulinemia in normal rodents, suggesting insulin resistance [14-16]. In a rat model prone to insulin resistance, SIR decreases Akt (also known as protein kinase B) phosphorylation (ser 473) in the liver, which is a key step in insulin signal transduction [39]. In summary, SIR induces insulin resistance and may reduce insulin secretion.

Treatment of PTDM involves similar strategies to those used for treatment of type 2 diabetes in the non-transplant population; lifestyle modification, oral anti-hyperglycemic agents, and/or insulin [40,41] Although there is abundant data in the non-transplant population showing type 2 diabetes can be prevented by weight loss and a variety of antihyperglycemic medications, no studies have evaluated strategies to prevent PTDM [42], although there are ongoing studies to evaluate the effects of dipeptidyl peptidase- 4 inhibitors on PTDM (Clinical trials number, NCT00936663, NCT01346254).

\section{Immunosuppression and Reproductive Dysfunction}

Reproductive dysfunction is a concern to many recipients after transplantation. Fertility improves in many women with chronic kidney disease after kidney transplantation [43]. Therefore, female recipients should be counseled about risks of pregnancy immediately after transplant. Conversely, hypogonadism has also been reported after transplantation, with $50 \%$ of women having menstrual cycle disorders after kidney transplantation in one study [44]. Our studies on women after pancreas transplantation revealed that half of the women reported amenorrhea, had evidence of primary hypogonadism, or menstrual irregularity pre-transplant, and $70 \%$ of women still had abnormal menstrual cycles one year after transplant, treated with predominantly cyclosporine or tacrolimus-based immunosuppression [45].

There are many causes of menstrual irregularity. Both corticosteroids and weight gain are associated with menstrual irregularity and decreased fertility [46]. In regards to the effect of other immunosuppressants on menstrual irregularity, there is paucity of data. Menstrual cycle abnormalities and ovarian cysts have been reported in type 1 diabetes patients after islet transplant using tacrolimus-sirolimus immunosuppression [47]. Our studies have shown that tacrolimus and sirolimus, individually or in combination interrupt cycling in normal animals [15]. Transient disruption of the reproductive system, especially in females, result from stress, including recent surgery, acute rejection, or infections, while more permanent compromise of ovarian blood supply and function can occur from pelvic surgery.

Pregnancy outcomes and paternity after transplant are tracked by the National Transplant Pregnancy Registry [48]. Hypertension, infection, pre-eclampsia and graft loss are some of the important consequences of pregnancy to the mother after transplantation [48]. Significant adverse effects to the infant include spontaneous abortions, prematurity, low birth weight and newborn [48]. No significant increase in fetal malformations has been reported to date. Due to the above mentioned significant risks of pregnancy to the mother and infant after transplantation, pregnancy after transplant should be considered a "high risk" pregnancy. The transplant team should encourage planning a desired pregnancy, with the transplant team, staying involved in the management of the pregnant transplant recipient. Immunosuppressant doses may also need to be altered during pregnancy, as sex steroid concentrations can affect metabolism of many immunosuppressant medications.

Hence, women should consider postponing pregnancy until after the first year of transplant when risks to both the mother and the baby are potentially lower, as risk of rejection is reduced and lower medication doses are needed. Pregnancy in the transplant patient under immunosuppressant therapy requires consideration of the agents used. Corticosteroids are used routinely in pregnancy (category B, as defined by FDA) [49]. Cyclosporine or tacrolimus have not been shown to significantly impact pregnancy outcomes (Category C) [48]. Sirolimus use during pregnancy was not associated with adverse outcomes to the mother or infant, according to few published case reports [50,51]. However, due to its known effects on cell growth and proliferation its use should be avoided in pregnancy until more data is available. 


\begin{tabular}{|l|l|l|}
\hline Immunosuppressant medication & $\begin{array}{l}\text { Mechanism of } \\
\text { immunosuppressant action }\end{array}$ & Endocrine dysfunction \\
\hline Tacrolimus (FK506)/ Cyclosporine & Calcineurin inhibition & $\begin{array}{l}\text { 1. Hyperglycemia: Beta cell toxicity, decreased insulin secretion and insulin sensitivity } \\
\text { PTDM [16,21,22,26,28,29]. }\end{array}$ \\
\hline Sirolimus (rapamycin) & $\begin{array}{l}\text { 2. Hypogonadism/oligospermia: rarely [53]. } \\
\text { 3. Low bone density: Cyclosporine has strong evidence while TAC has equivocal effects } \\
\text { [60-62,64]. }\end{array}$ \\
\hline & mTOR inhibition & $\begin{array}{l}\text { 1. Hyperglycemia: Insulin resistance and beta cell toxicity [14-16,37]. } \\
\text { 2. Primary hypogonadism in men and rarely reduced sperm counts [54-58]. } \\
\text { 3. May impair fracture healing [67]. }\end{array}$ \\
\hline
\end{tabular}

Table 1: Summary of effects of TAC and SIR on endocrine system

Mycophenolate mofetil use has been associated with fetal anomalies in a few case reports, suggesting its risk is not yet established and should likely be avoided for now [52]. Certain immunosuppressants, such as azathioprine (category D), should not be used in pregnancy. Since the risk of maternal immunosuppression is unknown in the breast-fed infant, concentrations of immunosuppressants should be monitored in infant, if breast feeding is practiced.

Men's reproductive function is also potentially affected by immunosuppression. Men treated with cyclosporine or tacrolimus after kidney or pancreas transplant appear to be rarely associated with oligospermia or hypogonadism [53]. However, rapamycin-based regimens after kidney transplant alone have been associated with reduced sperm count, decreased motility, and reduced fathered pregnancy rates [54-56]. Rapamycin has also been reported to lower testosterone and raise gonadotropins after kidney and cardiac transplant, suggesting a direct anti-gonadal effect of this medication [55,57,58]. While fewer patients have been treated to date, a newer mTOR inhibitor, everolimus, has not been associated with hypogonadism [55]. Risk to babies fathered by transplant recipients is being monitored, but no adverse effects have yet been reported [48]. One study reported that male recipients of kidney transplant who father offspring within $2 \mathrm{yr}$ of transplantation had higher rates of pre-term birth as compared to those who conceived 2 yrs after transplantation [59].

In summary, improvement of hypogonadism and fertility is observed after transplant ion. Menstrual irregularity is still common in women after transplantation, likely due to multiple causes. The only clear evidence of immunosuppression associated hypogonadism appears to be with sirolimus, especially primary hypogonadism in men after transplantation. Evidence of the contribution of other immunosuppressants to reproductive dysfunction after transplantation is not established. Although the effects of immunosuppression on fetal anomalies and to the breast-fed infant are not clear, pregnancy after transplantation should be considered high risk and treated as such.

\section{Immunosuppression and Bone Density}

Another potential endocrine-related problem associated with immunosuppression is decreased bone density. Corticosteroids have a distinct connection to bone health, however, other immunosuppressive agents are not so clearly related and results have been equivocal. Animal and human studies suggest that other than corticosteroids, cyclosporine has the most deleterious effects on bone metabolism among the various immunosuppressant agents [60-62]. An important contributor to low bone mass is hypophosphatemia which is associated with cyclosporine and sirolimus therapy, with sirolimus appearing to cause more persistent hypophosphatemia than cyclosporine [63]. Effects of tacrolimus on bone metabolism appear to be equivocal, with older animal studies suggesting that tacrolimus negatively affected bone metabolism, but more recent animal studies found no significant effect $[62,64]$. Animal studies may not translate to humans as clinical studies have not always conclusively shown an effect of calcineurins or sirolimus on bone mass [64-66]. However, due to the known negative impact of sirolimus on cell growth, it is plausible that sirolimus may impair healing following bone fracture [67].

In summary, although the goal of these drugs is to dampen the rejection of the transplant by the immune system, they clearly have effects in cells of the endocrine system and their target organs. The predominant effects of the commonly used immunosuppressants such as tacrolimus and sirolimus on the endocrine system appear to be on post-transplant diabetes and reproductive dysfunction, with equivocal evidence on their contribution to lowering bone density and increasing likelihood of fractures (Table 1). As PTDM has implication on graft and host survival, aggressive strategies to screen and treat PTDM should be employed in recipients of solid organ transplantation. Studies on prevention of PTDM are ongoing. Fertility tends to improve after transplantation, and thus female recipients should be counseled on the risk of immunosuppression during pregnancy, post-transplant.

\section{Acknowledgements}

This work was done at the VA Nebraska-Western lowa Health Care System and is based upon work supported in part by the Department of Veterans Affairs Veterans Health Administration, Office of Research and Development and Biomedical Laboratory Research and Development (Career Development Award: V.S).

\section{Disclaimer}

The contents do not represent the views of the Department of Veterans Affairs or the United States Government.

\section{References}

1. Hjelmesaeth J, Hartmann A, Leivestad T, Holdaas H, Sagedal S, et al. (2006) The impact of early-diagnosed new-onset post-transplantation diabetes mellitus on survival and major cardiac events. Kidney Int 69: 588-595.

2. Kasiske BL, Snyder JJ, Gilbertson D, Matas AJ (2003) Diabetes mellitus after kidney transplantation in the United States. Am J Transplant 3: 178-185.

3. John PR, Thuluvath PJ (2002) Outcome of patients with new-onset diabetes mellitus after liver transplantation compared with those without diabetes mellitus. Liver Transpl 8: 708-713.

4. Yates CJ, Fourlanos S, Hjelmesaeth J, Colman PG, Cohney SJ (2011) NewOnset Diabetes After Kidney Transplantation-Changes and Challenges. Am J Transplant.

5. Davidson J, Wilkinson A, Dantal J, Dotta F, Haller H et al. (2003) New-onse diabetes after transplantation: 2003 International consensus guidelines. Proceedings of an international expert panel meeting. Barcelona, Spain, 19 February 2003. Transplantation 75: SS3-SS24.

6. Montori VM, Basu A, Erwin PJ, Velosa JA, Gabriel SE, et al. (2002) Posttransplantation diabetes: a systematic review of the literature. Diabetes Care 25: 583-592.

7. Sulanc E, Lane JT, Puumala SE, Groggel GC, Wrenshall LE, et al. (2005) Newonset diabetes after kidney transplantation: an application of 2003 International Guidelines. Transplantation 80: 945-952.

8. Reynolds NJ, Al-Daraji WI (2002) Calcineurin inhibitors and sirolimus: mechanisms of action and applications in dermatology. Clin Exp Dermatol 27: 555-561.

9. Halloran PF (2001) Mechanism of action of the calcineurin inhibitors. Transplant Proc 33: 3067-3069. 
10. Bierer BE, Mattila PS, Standaert RF, Herzenberg LA, Burakoff SJ, et al. (1990) Two distinct signal transmission pathways in T lymphocytes are inhibited by complexes formed between an immunophilin and either FK506 or rapamycin. Proc Natl Acad Sci U S A 87: 9231-9235.

11. Halloran PF (2000) Sirolimus and cyclosporin for renal transplantation. Lance 356: 179-180.

12. Cosio FG, Pesavento TE, Osei K, Henry ML, Ferguson RM (2001) Posttransplant diabetes mellitus: increasing incidence in renal allograft recipients transplanted in recent years. Kidney Int 59: 732-737.

13. Pirsch JD, Miller J, Deierhoi MH, Vincenti F, Filo RS (1997) A comparison of tacrolimus (FK506) and cyclosporine for immunosuppression after cadaveric renal transplantation. FK506 Kidney Transplant Study Group. Transplantation 63: 977-983.

14. Shivaswamy V, McClure M, Passer J, Frahm C, Ochsner L, et al. (2010) Hyperglycemia induced by tacrolimus and sirolimus is reversible in normal sprague-dawley rats. Endocrine 37: 489-496.

15. Shivaswamy V, Ochsner L, Maroni D, Wang C, Passer J, et al. (2011) Tacrolimus and sirolimus induce reproductive abnormalities in female rats. Transplantation 91: 1333-1339.

16. Larsen JL, Bennett RG, Burkman T, Ramirez AL, Yamamoto S, et al. (2006) Tacrolimus and sirolimus cause insulin resistance in normal sprague dawley rats. Transplantation 82: 466-470.

17. Vincenti F, Friman S, Scheuermann E, Rostaing L, Jenssen T, et al. (2007) Results of an international, randomized trial comparing glucose metabolism disorders and outcome with cyclosporine versus tacrolimus. Am J Transplant 7: 1506-1514.

18. Woodward RS, Schnitzler MA, Baty J, Lowell JA, Lopez-Rocafort L, et al. (2003) Incidence and cost of new onset diabetes mellitus among U.S. waitlisted and transplanted renal allograft recipients. Am J Transplant 3: 590-598.

19. American Diabetes Association (2011) Standards of medical care in diabetes--2011. Diabetes Care 34: S11-S61.

20. Porrini E, Moreno JM, Osuna A, Benitez R, Lampreabe I, et al. (2008) Prediabetes in patients receiving tacrolimus in the first year after kidney transplantation: a prospective and multicenter study. Transplantation 85: 11331138.

21. Crutchlow MF, Bloom RD (2007) Transplant-associated hyperglycemia: a new look at an old problem. Clin J Am Soc Nephrol 2: 343-355.

22. Hjelmesaeth J, Jenssen T, Hagen M, Egeland T, Hartmann A (2003) Determinants of insulin secretion after renal transplantation. Metabolism 52 573-578.

23. Oetjen E, Baun D, Beimesche S, Krause D, Cierny I, et al. (2003) Inhibition of human insulin gene transcription by the immunosuppressive drugs cyclosporin A and tacrolimus in primary, mature islets of transgenic mice. Mol Pharmacol 63: $1289-1295$

24. Radu RG, Fujimoto S, Mukai E, Takehiro M, Shimono D, et al. (2005) Tacrolimus suppresses glucose-induced insulin release from pancreatic islets by reducing glucokinase activity. Am J Physiol Endocrinol Metab 288: E365-E371.

25. Redmon JB, Olson LK, Armstrong MB, Greene MJ, Robertson RP (1996) Effects of tacrolimus (FK506) on human insulin gene expression, insulin mRNA levels, and insulin secretion in HIT-T15 cells. J Clin Invest 98: 2786-2793.

26. Johnson JD, Ao Z, Ao P, Li H, Dai LJ, et al. (2009) Different effects of FK506 rapamycin, and mycophenolate mofetil on glucose-stimulated insulin release and apoptosis in human islets. Cell Transplant 18: 833-845.

27. Drachenberg CB, Klassen DK, Weir MR, Wiland A, Fink JC, et al. (1999) Islet cell damage associated with tacrolimus and cyclosporine: morphological features in pancreas allograft biopsies and clinical correlation. Transplantation 68: $396-402$

28. Sui W, Zou H, Zou G, Yan Q, Chen H, et al. (2008) Clinical study of the risk factors of insulin resistance and metabolic syndrome after kidney transplantation. Transpl Immunol 20: 95-98.

29. Wyzgal J, Paczek L, Sanko-Resmer J, Ciszek M, Nowak M, et al. (2007) Insulin resistance in kidney allograft recipients treated with calcineurin inhibitors. Ann Transplant 12: 26-29.

30. Van Laecke S, Van Biesen W, Verbeke F, De Bacquer D, Peeters P, et al. (2009) Posttransplantation hypomagnesemia and its relation with immunosuppression as predictors of new-onset diabetes after transplantation. Am J Transplant 9 : 2140-2149.
31. Gueux E, Rayssiguier Y (1983) The effect of magnesium deficiency on glucose stimulated insulin secretion in rats. Horm Metab Res 15: 594-597.

32. Dzurik R, Stefikova K, Spustova V, Fetkovska N (1991) The role of magnesium deficiency in insulin resistance: an in vitro study. J Hypertens Suppl 9 : S312-S313.

33. Veroux M, Corona D, Giuffrida G, Gagliano M, Sorbello M, et al. (2008) New-onset diabetes mellitus after kidney transplantation: the role of immunosuppression. Transplant Proc 40: 1885-1887.

34. Johnston O, Rose CL, Webster AC, Gill JS (2008) Sirolimus is associated with new-onset diabetes in kidney transplant recipients. J Am Soc Nephrol 19: 1411-1418.

35. Bussiere CT, Lakey JR, Shapiro AM, Korbutt GS (2006) The impact of the mTOR inhibitor sirolimus on the proliferation and function of pancreatic islets and ductal cells. Diabetologia 49: 2341-2349.

36. Bell E, Cao X, Moibi JA, Greene SR, Young R, et al. (2003) Rapamycin has a deleterious effect on MIN-6 cells and rat and human islets. Diabetes 52: 2731 2739 .

37. Zahr E, Molano RD, Pileggi A, Ichii H, Jose SS, et al. (2007) Rapamycin impairs in vivo proliferation of islet beta-cells. Transplantation 84: 1576-1583.

38. Hakeam HA, Al-Jedai AH, Raza SM, Hamawi K (2008) Sirolimus induced dyslipidemia in tacrolimus based vs. tacrolimus free immunosuppressive regimens in renal transplant recipients. Ann Transplant 13: 46-53.

39. Fraenkel M, Ketzinel-Gilad M, Ariav Y, Pappo O, Karaca M, et al. (2008) mTOR inhibition by rapamycin prevents beta-cell adaptation to hyperglycemia and exacerbates the metabolic state in type 2 diabetes. Diabetes 57: 945-957.

40. Lane JT, Dagogo-Jack S (2011) Approach to the Patient with New-Onse Diabetes after Transplant (NODAT). J Clin Endocrinol Metab 96: 3289-3297.

41. Jenssen T, Hartmann A (2011) Prevention and management of transplantassociated diabetes. Expert Opin Pharmacother 12: 2641-2655

42. DeFronzo RA, Abdul-Ghani MA (2011) Preservation of beta-cell function: the key to diabetes prevention. J Clin Endocrinol Metab 96: 2354-2366.

43. Zachariah MS, Tornatore KM, Venuto RC (2009) Kidney transplantation and pregnancy. Curr Opin Organ Transplant 14: 386-391.

44. Tauchmanova L, Carrano R, Sabbatini M, De Rosa M, Orio F, et al. (2004) Hypothalamic-pituitary-gonadal axis function after successful kidney transplantation in men and women. Hum Reprod 19: 867-873.

45. Mack-Shipman LR, Ratanasuwan T, Leone JP, Miller SA, Lyden ER, et al. (2000) Reproductive hormones after pancreas transplantation. Transplantation 70: $1180-1183$

46. Lado-Abeal J, Rodriguez-Arnao J, Newell-Price JD, Perry LA, Grossman $A B$, et al. (1998) Menstrual abnormalities in women with Cushing's disease are correlated with hypercortisolemia rather than raised circulating androgen levels. J Clin Endocrinol Metab 83: 3083-3088.

47. Cure P, Pileggi A, Froud T, Norris PM, Baidal DA, et al. (2004) Alterations of the female reproductive system in recipients of islet grafts. Transplantation 78 1576-1581.

48. Coscia LA, Constantinescu S, Moritz MJ, Radomski JS, Gaughan WJ, et al. (2007) Report from the National Transplantation Pregnancy Registry (NTPR) outcomes of pregnancy after transplantation. Clin Transpl pp. 29-42.

49. http://depts.washington.edu/druginfo/Formulary/Pregnancy.pdf.

50. Chu SH, Liu KL, Chiang YJ, Wang HH, Lai PC (2008) Sirolimus used during pregnancy in a living related renal transplant recipient: a case report. Transplant Proc 40: 2446-2448.

51. Framarino dei Malatesta M, Corona LE, De Luca L, Rocca B, Manzia TM, et al. (2011) Successful pregnancy in a living-related kidney transplant recipient who received sirolimus throughout the whole gestation. Transplantation 91 e69-e71.

52. Sifontis NM, Coscia LA, Constantinescu S, Lavelanet AF, Moritz MJ, et al (2006) Pregnancy outcomes in solid organ transplant recipients with exposure to mycophenolate mofetil or sirolimus. Transplantation 82: 1698-1702.

53. Kantarci G, Sahin S, Uras AR, Ergin H (2004) Effects of different calcineurin inhibitors on sex hormone levels in transplanted male patients. Transplant Proc 36: $178-179$.

54. Bererhi L, Flamant M, Martinez F, Karras A, Thervet E, et al. (2003) Rapamycininduced oligospermia. Transplantation 76: 885-886. 
55. Huyghe E, Zairi A, Nohra J, Kamar N, Plante P, et al. (2007) Gonadal impact of target of rapamycin inhibitors (sirolimus and everolimus) in male patients: an overview. Transpl Int 20: 305-311.

56. Zuber J, Anglicheau D, Elie C, Bererhi L, Timsit MO, et al. (2008) Sirolimus may reduce fertility in male renal transplant recipients. Am J Transplant 8: 14711479

57. Kaczmarek I, Groetzner J, Adamidis I, Landwehr P, Mueller M, et al. (2004) Sirolimus impairs gonadal function in heart transplant recipients. Am J Transplant 4: 1084-1088.

58. Lee S, Coco M, Greenstein SM, Schechner RS, Tellis VA, et al. (2005) The effect of sirolimus on sex hormone levels of male renal transplant recipients. Clin Transplant 19: 162-167.

59. Xu LG, Jin LM, Zhu XF, Song QZ, Ding XF, et al. (2008) A report of 212 male renal transplant recipients who fathered 216 offspring after transplantation. Transplantation 86: 1480-1481.

60. Movsowitz C, Epstein S, Fallon M, Ismail F, Thomas S (1988) Cyclosporin-A in vivo produces severe osteopenia in the rat: effect of dose and duration of administration. Endocrinology 123: 2571-2577.
61. Goodman GR, Dissanayake IR, Sodam BR, Gorodetsky E, Lu J, et al. (2001) Immunosuppressant use without bone loss--implications for bone loss after transplantation. J Bone Miner Res 16: 72-78.

62. Spolidorio LC, Nassar PO, Nassar CA, Spolidorio DM, Muscara MN (2007) Conversion of immunosuppressive monotherapy from cyclosporin a to tacrolimus reverses bone loss in rats. Calcif Tissue Int 81: 114-123.

63. Morales JM, Wramner L, Kreis H, Durand D, Campistol JM, et al. (2002) Sirolimus does not exhibit nephrotoxicity compared to cyclosporine in renal transplant recipients. Am J Transplant 2: 436-442.

64. Epstein S (1996) Post-transplantation bone disease: the role of immunosuppressive agents and the skeleton. J Bone Miner Res 11: 1-7.

65. Sprague SM, Josephson MA (2004) Bone disease after kidney transplantation. Semin Nephrol 24: 82-90.

66. Mitterbauer C, Oberbauer R (2008) Bone disease after kidney transplantation. Transpl Int 21: 615-624.

67. Holstein JH, Klein M, Garcia P, Histing T, Culemann U, et al. (2008) Rapamycin affects early fracture healing in mice. Br J Pharmacol 154: 1055-1062.
This article was originally published in a special issue, Endothelial Keratoplasty handled by Editor(s). Dr. Jodhbir S Mehta, Singapore Eye Research Institute, (SERI), Singapore; Dr. Saijad Ahmad, Newcastle University, United Kingdom 